\title{
JOGOS DIGITAIS E ENSINO DE HISTÓRIA: O USO DO ROLE PLAYING GAME (RPG) NO ENSINO INTERDISCIPLINAR ONLINE SOBRE A COMUNIDADE DOS PAÍSES DE LÍNGUA PORTUGUESA (CPLP)
}

\author{
SALVADOR/BA JULHO/2018
}

\author{
Bianca e Silva Cardoso - UNEB - biancascardoso@gmail.com \\ Alfredo Eurico Rodrigues Matta - UNEB - alfredomatta@gmail.com \\ Tipo: Investigação Científica (IC) \\ Natureza: Descrição de Projeto em Andamento \\ Categoria: Métodos e Tecnologias \\ Setor Educacional: EDUCAÇÃO MÉDIA E TECNOLÓGICA
}

\begin{abstract}
RESUMO
O presente artigo relata a experiência do desenvolvimento de um jogo RPG - Role Playing Game como instrumentos tecnológicos para o ensino de História interdisciplinar online sobre a Comunidade dos Países de Língua Portuguesa (CPLP). Para tanto, consideramos o potencial de uma Comunidade Internacional de Aprendizagem em Língua Portuguesa proposta por Matta (2008), como comunidade de prática em EAD num contexto de globalização da educação. O jogo RPG digital tem sido objeto de estudo do grupo de pesquisa Sociedade em Rede, Pluralidade Cultural e Conteúdos Digitais Educacionais, sendo desenvolvidos inúmeros produtos que foram utilizados como instrumentos pedagógicos para a aprendizagem à distância. Todos os jogos de RPG Digital desenvolvidos pelo Grupo de Pesquisa foram frutos de pesquisas vinculadas aos programas de mestrado e doutorado da Universidade do Estado da Bahia. Buscou—se, com este projeto a possibilidade de um ensino de História interdisciplinar engajado na práxis e no contexto histórico de sua coletividade e de sua pluriculturalidade e polifonia, que fomente o pensamento reflexivo e envolva os sujeitos como agentes no processo de construção de conhecimento histórico e formação de uma identidade a partir da Língua Portuguesa. Usamos como base epistemológica Castell (1999), Matta (2008), Rodrigues (2004), Huizinga (2007), para fundamentar as questões sobre Sociedade em Rede, Tecnologias da Informação e Comunicação (TIC), Jogos Digitais e RPG para o Ensino. Vygotsky (2010), Martineau (1997), para centrar a proposta pedagógica no sócio-construtivismo, o no Modo de Pensar Histórico e suas características de trabalho cognitivo, com o objetivo de construir uma forma sócio construtivista de trabalho em EaD através dos jogos de simulação. Como metodologia, utilizamos a Design Based Research (DBR), ou metodologia por "proposta" como melhor seria entendida em português.
\end{abstract}

Palavras-chave: Jogo RPG, Design - Based Research, Educação à Distância, Ensino de História

AGRADECIMENTOS

AO PROGRAMA DE PÓS-GRADUAÇÃo EM EDUCAÇÃo E CONTEMPORANEIDADE (PPGEDUC/UNEB), AO GP SOCIEDADE EM REDE, PLURALIDADE CULTURAL E CONTEÚDOS DIGITAIS EDUCACIONAIS E A CAPES PELO APOIO À PESQUISA. 


\section{Introdução}

Com a consolidação dos cursos à distância no Brasil, a aprendizagem mediada por computadores mostra-se cada vez mais concreta, e em consequência desse movimento, surgem inúmeras investigações no campo da aprendizagem online. O referente artigo enquadra-se nesse universo de pesquisas, e propôs uma investigação nesse campo de aprendizagem. A partir das investigações do grupo de pesquisa Sociedade em Rede, Pluralidade Cultural e Conteúdos Digitais Educacionais, vinculadas aos programas de mestrado e doutorado da Universidade do Estado da Bahia, identificou-se a inexistência de um modelo de Jogo RPG Digital em Rede Colaborativa que conduza o ensinoaprendizagem interdisciplinar em História online sobre a Comunidade dos Países de Língua Portuguesa (CPLP). Por se tratar do quinto idioma mais falado no planeta, tal expressão portuguesa transcende a questão do idioma e o território do qual é falado, configurando espaços de similitudes culturais que não mais obedecem a uma fronteira nacional, compondo uma Comunidade Internacional de Aprendizagem. Nesse sentido, propomos a construção de um instrumento de mediação da aprendizagem em EAD, que possa ser utilizada em diferentes países, pois os indivíduos compartilham da mesma experiência sociocultural, interétnicas, embora sejam plenos de pluralidade.

Sendo assim, apresentaremos neste artigo os resultados finais de projeto de mestrado em fase de defesa e as respectivas reflexões que nos levaram a proposta de jogo, que teve como objetivo principal o desenvolvimento de um modelo de RPG Digital mediador do ensino de História interdisciplinar online sobre a Comunidade dos Países de Língua Portuguesa (CPLP).

\section{Referencial Teórico}

A CPLP é composta principalmente por Angola, Brasil, Cabo Verde, Guiné-Bissau, Moçambique, Portugal, São Tomé e Príncipe e Timor-Leste, que juntos somam aproximadamente 250 milhões de pessoas, transformando o português no quinto idioma mais falado no mundo. Além destes há outros tantos países de comunidades lusófonas importantes. Nesse aspecto, é importante explorar o potencial dessa comunidade enquanto comunidade de aprendizagem. Segundo dados do site institucional do grupo, a CPLP foi criada oficialmente em Junho de 1996 com a realização da Cimeira de Chefes de Estado e de Governo, teve como participantes os chefes de governo de sete países, sendo Timor Leste, incorporado à comunidade somente em 2002. A CPLP tem como objetivo principal, a materialização de projetos de promoção e difusão da língua portuguesa, através de articulações realizadas pelos membros. Considerando a autonomia política desses países, a CPLP considera em seus princípios, as 
particularidades de cada nação, "por compreender um foromultilateral privilegiado para o aprofundamento da amizade mútua e da cooperação entre os seus membros".

A praxiologia gramsciana (1978) compreende a História como processos contínuos de interação de seres humanos em diferentes ambientes, estabelecendo fluxos [e refluxos] de tensões e contradições, resultando em continuidades da narrativa histórica. De início, ressalvo que a construção desse contexto não tem a pretensão de esgotar as discussões e abordagens sobre o processo de formação, construção e interação entre as nações de expressão portuguesa, mas sim trazer a tona uma das perspectivas para que possamos validar como próxima da interpretação que damos e assumimos para a História desses povos.

Para tanto, é preciso compreender como se processa a aprendizagem, bem como a aprendizagem interdisciplinar em história online. Essa compreensão baseia-se nos princípios cognitivos Sócio-construtivistas de Vygotsky (1998), que concebe a educação e os fenômenos educacionais como um constante devir, um constante movimento, mediado pelos professores e outros alunos, imbricado num contexto sócio-histórico e cultural em comum.

Entretanto por se tratar de ensino a distância, as discussões sobre Tecnologia de Aprendizagem, discutido por (MATTA, 2006), são fundamentais, uma vez que, na aprendizagem mediada por computadores existem elementos favorecedores para a contemporaneidade, considerando que a sociedade informatizada da qual vivemos, configura-se como interligada e constantemente em transformação. Manuel Castells (1999), define a sociedade atual como fruto de uma cibercultura. Entendendo essa característica como resultado de uma "prática cultural contextualizada pela emergência dos ambientes informatizados" (MATTA, 2006, p. 25), a sociedade informatizada redefiniu (ou foi moldada pelas) as demandas mercadológicas, no que se refere ao perfil de trabalhadores, bem como estabeleceu novas habilidades e competências para o desenvolvimento de técnicas e estratégias profissionais que passaram a fundamentar a nossa sociedade. Nesse sentido, a Sociedade em Rede, aqui evidenciada, estabelece a interação e a intercomunicação contínua entre os membros (todos nós inseridos nela), por meio de uma notável e ampla rede colaborativa, que gera uma "gama enorme de comunidades virtuais" (CASTELLS, 1999).

Nesse contexto, podemos destacar essa sociedade em transformação como principal fomentadora do surgimento, ampliação e aperfeiçoamento do ensino a distancia no Brasil e no mundo. Forjada numa trajetória desde o enunciado na Gazeta de Boston em 
1728 (EUA), e expandindo-se pelos demais países nos séculos seguintes, a EAD utilizou diferentes meios de comunicação como difusores do conhecimento, desde anúncios de jornais a computadores ligados a internet, passando pelos correios e programa de rádio e televisão. A educação a distancia atualmente apresenta-se como forte possibilidade educativa interativa e não linear, propiciando uma maior autonomia dos estudantes bem como possibilita o diálogos com outros sujeitos envolvidos no mesmo processo. Em função disso, considero a relevância do alcance dessa modalidade de ensino e concebo a Comunidade de Aprendizagem Internacional em Língua Portuguesa como grupo de importante potencial no processo de ensinoaprendizagem.

No caso dessa pesquisa, focado no ensino de História numa comunidade internacional, faz-se necessário um modelo de ensino norteado pela constante estimulação da crítica, seja no que tange a narrativa histórica, quanto aos processos históricos. Esse raciocínio crítico pode ser equiparado ao raciocínio histórico, segundo Martineau (1997) que deve ser estimulado, relacionando conteúdos problematizados de História às experiências vivenciadas pelos estudantes, pois, ainda segundo o autor, a própria História é resultante de produção intelectual do historiador. Esse modo de pensar histórico operase a partir de quatro estágios: a) Estágio 1: Formular hipóteses a partir das questõesproblemas apresentadas; b) Estágio 2: Procurar e criticar fontes de informação; c) Estágio 3: Interpretar as informações; d) Estágio 4: Tirar conclusões ou chegar a uma síntese interpretativa à problematização inicial. Lembrando que, o modo de pensar histórico estimulado em sala, presumivelmente será aplicado, por esses estudantes, em seus contextos sócio-culturais.

Nas últimas décadas, como tentativa de buscar metodologias que aproximassem os estudantes dos conteúdos a serem aprendidos na escola, muitos docentes passaram a utilizar jogos para mediar o ensino. As brincadeiras e os jogos atuam, segundo Vygotsky (1998), na zona de desenvolvimento imediato, portanto podem servir como instrumentos para mediação da aprendizagem. Para tanto, é preciso definir o conceito de jogo que utilizaremos. De acordo com o filósofo Johan Huizinga (2007, p. 33), o jogo é uma atividade voluntária, realizada em determinados limites de tempo e regras préestabelecidas e, portanto aceitas, com um fim em si mesmo, acompanhado de um misto de alegria e tensão, diferenciado da vida cotidiana. Portanto, podemos identificar aspectos fundamentais do jogo defendido por Huizinga, que consiste em: a) liberdade, já que se caracteriza por uma ocupação voluntária; b) discernimento, pois se faz notória a distinção entre vida "real" e o jogo, e c) lucidez, pois se difere da vida cotidiana, uma vez que o tempo e o espaço são limitados pelas regras do jogo. 
Contudo, o jogo que escolhemos para utilizar como mediador da aprendizagem é o Role Playing Game (RPG), que significa, em livre tradução, jogo de interpretação de papel. $O$ RPG surgiu nos Estados Unidos, na década de 1970, chegando ao Brasil nos anos de 1990, com a Geração Xerox. O jogo é composto por um sistema de regras pré-definido, onde os jogadores, a partir das características do personagem escolhido, buscam através de estratégias (individuais e/ou coletivas) resoluções de problemas apresentados nas tramas da história pelo Mestre (aquele que constrói e elabora as aventuras, que também tem o papel de guiar e controlar 0 jogo). Existem várias maneiras de se jogar o RPG, para essa pesquisa o jogo será realizado a partir de plataformas virtuais, jogado entre diversos usuários simultaneamente pela internet, o RPG Digital. Segundo a primorosa definição de Sonia Rodrigues (2004), o RPG é uma "mistura de 'faz de conta' com o velho hábito de contar histórias, entrelaçamento da literatura com roteiro de televisão e de cinema" (2004, p.18). Considerando as demandas levantadas nesse artigo, ouso afirmar que o RPG apresenta-se como instrumento pedagógico capaz de atender as demandas levantadas para buscar uma maior eficácia no processo de ensino-aprendizagem. No que tange às novas abordagens do ensino de História, nada como aprender interpretando papéis de personagens, simulando o contexto histórico de diferentes perspectivas, engajados e envolvidos nos problemas da temporalidade em questão, sem deixar escapar as próprias referências.

Do ponto de vista pedagógico, o socioconstrutivismo aparece como característica inerente ao jogo RPG, pois os princípios da aprendizagem vygotskiana abordados na pesquisa fazem parte da dinâmica ligado do jogo. Todas essas características serão fundamentais na construção da campanha e das aventuras do jogo, considerando, sobretudo o ensino online de História (e sua narrativa) como teia de um aprendizado interdisciplinar. Pela liberdade inerente à produção literária e a comum utilização de narrativas imaginativas, o RPG aplicado ao ensino de História, possibilita a abordagem de diferentes culturas em diferentes períodos, podendo agregar conceitos e métodos de outras disciplinas, como por exemplo, geografia, antropologia, linguística, sociologia, filosofia, arqueologia, entre outras, incorporando mais um significativo benefício do uso desse instrumento pedagógico no cotidiano escolar. Pois as experiências vivenciadas pelos sujeitos aprendizes, não ocorrem de maneira compartimentada, fazendo-se necessário uma forma de mediar à aprendizagem que conceba a aplicação de conceitos interculturais e interdisciplinares.

\section{Procedimentos Metodológicos}

Com relação ao desenvolvimento da metodologia, apresentamos uma proposta atual e 
inovadora, que vem sendo utilizada em pesquisas aplicadas com tecnologias da informação e comunicação. Para a investigação sobre uma aplicação do Jogo RPG para o ensino de história interdisciplinar sobre as Comunidades dos Países de Língua Portuguesa, utilizaremos a metodologia Design-Based Research (DBR), ou método de desenvolvimento, como melhor vem sendo entendida em português.

A DBR possui cinco características: a) Teoria Orientada; b) Intervenção; c) colaboração; d) fundamentalmente responsiva; e) iteração. Esta proposta metodológica apresenta-se como a mais adequada ao estudo, pela característica de método de pesquisa aplicada. Em conformidade com os princípios de aplicação desta proposta metodológica dividimos a pesquisa em duas etapas: 1) a primeira etapa, conforme a DBR, é a construção de contexto e fundamentação para a elaboração de uma intervenção prática aplicada de Jogo digital RPG; 2) a segunda de desenvolvimento e séries de aplicações sistematicamente acompanhadas, com finalidade de desenvolvimento e inovação da prática social.

\section{Apresentação e discussão dos resultados}

Sendo assim, na primeira etapa, desenvolvemos uma pesquisa que busca resposta às questões norteadoras já enunciadas e o amadurecimento do contexto através de pesquisas exploratórias, levantamento documental e historiográfico, entrevistas, validações de modelo, e outras formas de elaborar, que se refiram às temáticas de ensino de história interdisciplinar, Comunidades de Aprendizagem Internacional em Língua Portuguesa e Jogo RPG, que compõem o estudo. Como resultados iniciais, podemos destacar: a) Uma interpretação do processo histórico da formação da Comunidade dos Países de Língua Portuguesa; b) Uma Construção de proposta didáticopedagógica para o ensino de história interdisciplinar; c) Uma proposta de jogo RPG construída a partir da pesquisa acima descrita. $O$ resultado desta primeira fase foi um conjunto de informações e construções capazes de nos fazer desenvolver o Jogo Digital proposto, RPG sobre o tema já indicado. Por conta das características da DBR, a primeira fase não deve ser considerada como finalizada, pois a partir das situações problemas, as indicações e colaborações dos envolvidos poderão ser acrescidas. A segunda fase consiste em, tendo desenvolvido o jogo, proceder na elaboração de uma série de aplicações do RPG Digital, nas quais variáveis dependentes e independentes norteará o jogo, sendo capaz de investigar quando à sua capacidade de: a) Prover a historiografia de mais uma linguagem de estudo e avanço de conhecimento histórico online, já que o RPG serve como simulação da História e pode reproduzir situações de discussão e diálogo historiográfico; b) Promover ensino-aprendizagem online de História relativo à comunidade de expressão portuguesa; c) Contribuir para o desenvolvimento 
de uma identidade de expressão portuguesa pluricultural online, de acordo com a Comunidade de Aprendizagem Internacional em Língua Portuguesa online.

\section{Considerações finais}

Considerando que a pesquisa em questão encontra-se em fase final de defesa no Mestrado, desde o início ficou evidenciado o desafio de se desenvolver pesquisa aplicada, onde os resultados podem apresentar um possível "insucesso" ou ineficiência do experimento. Entretanto, destaco como o primeiro triunfo da pesquisa, reside na escolha da metodologia DBR, uma vez que compreende um método que considera a incompletude da investigação. Com isso a DBR transforma os insucessos, que em outra modalidade de pesquisa inviabilizaria sua continuidade, em reformuladores da pesquisa.

Outro aspecto desafiador da pesquisa reside no desafio de construir um entendimento sobre a comunidade de expressão portuguesa, uma vez que compreende uma ampla rede cultural que interagem entre si, tornando muitas vezes difícil estabelecer um perfil proveniente de cada país. Esse perfil configura-se necessário para a construção dos personagens do jogo RPG online. A proposta pedagógica que será utilizada no jogo deverá propiciar a construção do conhecimento de historiográfico amparado nos pressupostos de Vygotsky e de Martineau, com o intuito de desmistificar a ideia entre os estudantes de que o aprendizado histórico baseia-se em decorar as narrativas factuais, mas sim um aprendizado construído a partir de motivações, um aprendizado pautado nas reflexões e interpretações da ação de sujeitos históricos. A utilização do sócioconstrutivismo, aliado ao modo de pensar histórico, ancorada no método DBR propiciará o desenvolvimento do jogo RPG digital que, caso ateste a eficiência, será capaz de auxiliar na construção de conhecimento sobre o ensino de história interdisciplinar online sobre a comunidade dos países de língua portuguesa (CPLP). Considerando a potencialidade da Comunidade de Aprendizagem Internacional de expressão portuguesa.

\section{Referências}

CASTELLS, Manuel. A Sociedade em Rede. São Paulo. Paz e Terra, 1999.

COMUNIDADE dos Países de Língua Portuguesa. Disponível em: . Acesso em 29 de abril de 2017. ,

GRAMSCI, Antonio. Concepção dialética da História. Coleção Obras escolhidas. Tradução Manuel Cruz. São Paulo: Martins Fontes, 1978. 
HUIZINGA, Johan. Homo Iudens:o jogo como elemento da cultura. 5edição. São Paulo: Perspectiva, 2007.

MARTINEAU, Robert. L'Echec de l'apprentissage de la pensée historique á l'école secondaile. Contribuition á l'elaboration de fondaments didatiques pour enseigner l'Historie. Laval: Quebec, 1997.

MATTA, A. E. R.; SAMPAIO, I. A.; NONATO, E. S. Comunidades de aprendizagem internacionais de expressão portuguesa: a ação do Instituto Anísio Teixeira na Bahia e o primeiro curso internacional em Língua Portuguesa. Associação Brasileira de Ensino a Distância, 14 CIEAD - Congresso Internacional ABED de Educação à Distância, Santos/SP, $2008 . \quad$ Disponível em: http://www.abed.org.br/congresso2008/tc/612200830013PM.pdf

MATTA, Alfredo Eurico Rodrigues. Tecnologias de Aprendizagem em Rede e Ensino de História - utilizando comunidades de aprendizagem e hipercomposição. Brasília: Líber, 2006.

RODRIGUES, Sonia. Roleplaying Game e a Pedagogia da Imaginação no Brasil. Rio de Janeiro: Bertrand Brasil, 2004.

VYGOTSKY, Lev Semenovich. A formação social da mente. 6. ed. São Paulo: Martins Fontes, 1998.

VYGOTSKY, Lev. S. Aprendizagem e desenvolvimento intelectual na idade escolar. In: Linguagem, desenvolvimento e aprendizagem. Vygostky, L. Luria, A. Leontiev, A.N. 11‥ Edição. São Paulo: Ícone, 2010, p. 103-116. 